\title{
Developing Research Training Services at Asbury Seminary
}

Wesley D. Custer

Director of Instructional Services

Asbury Theological Seminary

\begin{abstract}
Research training services at Asbury Seminary have been under development for many years and have been provided by several different librarians through those years. This presentation covered who our patrons are in terms of demographics and degree programs. The discussion then turned to their needs for information literacy and research training in both information access and methodologies for research. Finally, we discussed new strategies for engaging patrons, including faculty engagement and curriculum assessment standards that push the issue of information literacy and research training into the curriculum.
\end{abstract}

\section{INTRODUCTION}

Thinking about this topic has been a focus of my reflection for the past year and a half. I have come to some conclusions about how I think research training can be implemented within the seminary. Before we get there, I want to describe our patrons. Then I will discuss the needs of our patrons-both felt and real needs. We will then talk about what Asbury Seminary has been doing for the past several years about research training. Finally, I will look at what the dream is and how we move forward from here. 


\section{DEFINING OUR PATRONS}

Figure 1: All images come from the Asbury Seminary Fact Sheet https://asburyseminary.edu/wp-content/uploads/quick-facts.pdf ${ }^{1}$

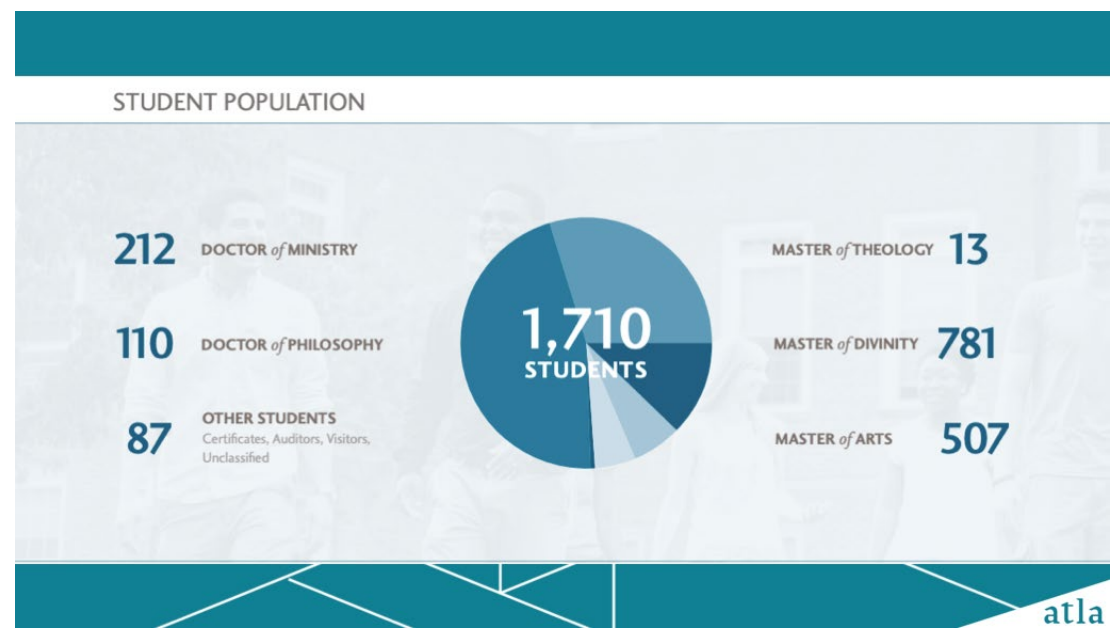

Who are our patrons? Asbury Theological Seminary has 1710 students spread between MDiv, MA and then ThM, DMin, and PhD programs. We also have many who are certificate-seeking students, both graduate certificates and lay-level certificates (see Figure 1). Due to the varied educational goals of our students, their needs are equally varied. Geographically, our students come from forty-one countries around the world while at the same time, $51 \%$ of our student body are classified as local students proximate to Wilmore (see Figure 2). Even that statistic can be misleading because our local housing is just far enough away that our students engage with the library online more than they do in person. This number also includes students who are primarily hybrid students commuting in to campus for most of their courses. 
Figure 2:

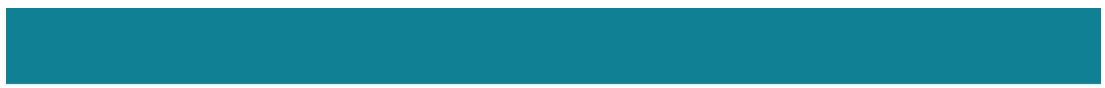

STUDENTS BY CAMPUS

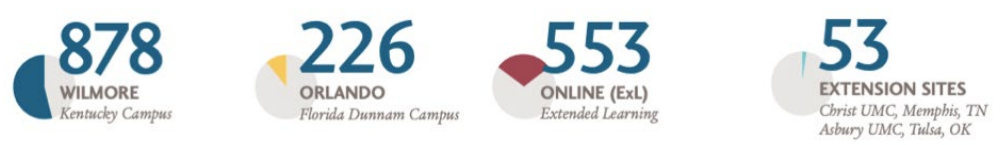

\section{$44 / 41$}

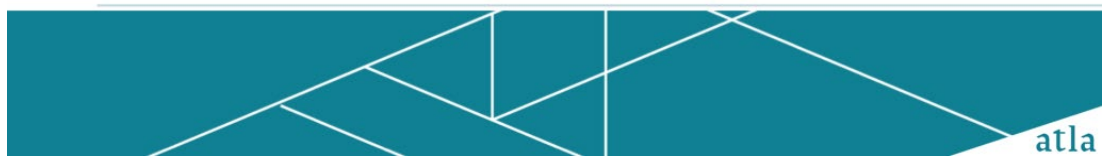

Our students are fairly diverse. In addition to the forty-one countries represented, Eighty-four denominations are represented among the student body. Thirty-seven-point-four percent of students are female and $44.2 \%$ self-identify as other than white/Caucasian. The ages of our students are fairly evenly spread from 20s to 60s. (See Figure 3 for these numbers.)

Figure 3:

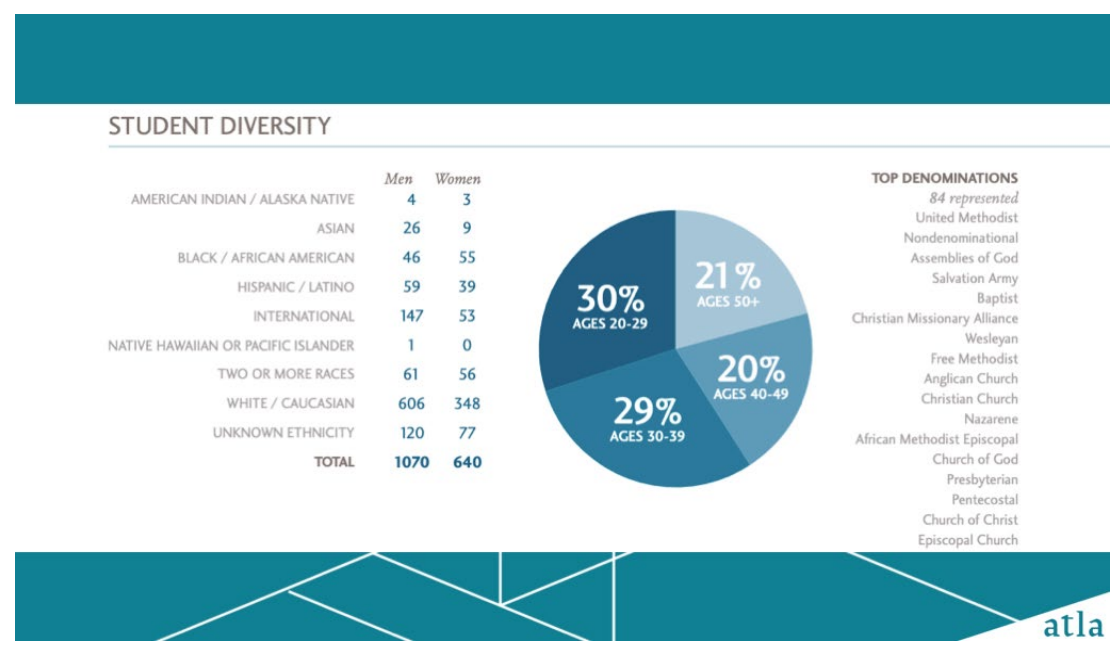


As you can see in Figure 4, the faculty is predominantly white, Caucasian, and male. The 147 adjunct instructors show more diversity of origin and perspective, representing seven different countries.

Figure 4:

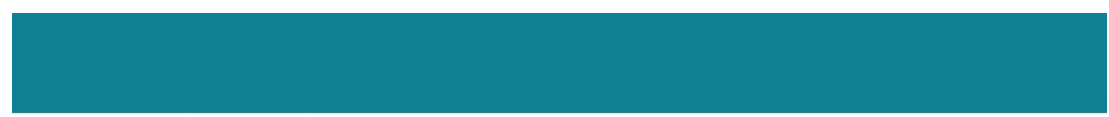

FACULTY DIVERSITY

Our faculty made $\mathbf{2 5}$ teaching trips to international

seminaries and universities in 14 countries in 2017-2018.

The teaching faculty collectively hold doctoral degrees from

46 institutions.

Our $\mathbf{1 4 7}$ adjunct professors hail from $\mathbf{2 7}$ states

and 7 countries. In 2017-2018, Asbury Seminary faculty

published 102 works.

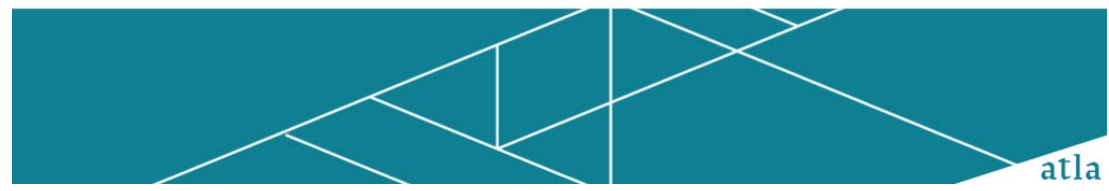

Most of our students are seeking education for engagement in parish ministry. They are all more likely to engage online even though they cannot finish a degree online alone. They may fulfill these non-online requirements at one of our extension locations or through short intensive instruction sessions on site.

When a student engages with the library they normally need basic information literacy. Instruction in this area is largely merely engaging with the library catalog and the online databases. They do not understand the difference between natural and controlled vocabulary nor do they understand the concept of indexing. Those issues are usually as far as our research instruction is able to go. Students seem to be confident in their own ability to conduct their research once they understand how to locate the information they think they are looking for. Occasionally, I am able to spend some time helping the student hone their topic and their research question. Those opportunities are too rare, and we rarely make it to the finer points of research methodology.

We do have a writing center, which is a likely resource for helping them with the finer points of writing up their research report or 
simply honing their grammar and expression. I feel like this is a bit of a luxury and if we did not have this resource, I would be working on that too or referring our students to outside consultants.

\section{BASIC STUDENT ASSUMPTIONS:}

I am certain that we have seen all of these: 1) They assume that research is just finding resources and that is all. 2) They assume that finding resources is just like Google. 3) They also assume that a good topic is "I want to research St. Augustine." 4) They also assume that the library is there to simply give them information and not teach them anything. "Give me what I want when I want it and I'll move on" is the mentality. 5) They also assume that they know what the research process is.

As Seneca the Younger is often paraphrased, "If you don't know to which harbor you are sailing, no wind is favorable." If the student does not know how to frame their topic or if they don't know the research method and/or their methodology that they are following, nothing that we give them is truly a favorable "wind." I might suggest that information is more like the water through which one sails rather than the wind that drives the boat forward.

Students need to know what they are looking for, why it is the right information, and how to find it, not just how to find information. The skill of finding information seems to be the main focus of my and my predecessors' instruction, and that is sad.

In many cases the basic need is framing a good research question. Then the student needs to answer the question: What kind of data is needed to answer this research question? Being able to delimit their data set and their research method and methodologies is the missing link in library instruction.

Many instruction resources focus on collecting and analyzing data as well as evaluation of the data source to determine its quality. This is necessary and important, but it is useless without well-defined methods and research goals. Then the student must write their research report! This poses its own difficulties and there are unique skills involved in meeting these needs. Developing a good thesis statement after researching or finding information is the first step.

Students regularly only turn to librarians when they need to polish 
their bibliography, but a bibliography is such a small (yet important) part of the writing process.

What tools have we been using? Well, we have the usual suspectsLibGuides and appointments both in the library and online. The LibGuides are good. They were written by those who came before me and they are fine. I find them lacking, however, the guidance and instruction needed to move students forward in their scholarship. Appointments are good, and they allow us to develop relationships with students. However, it is not scalable to provide one-on-one instruction to $1700+$ students.

For example, when a DMin student is working on their literature review they suddenly learn that they do not know how to find information, and regularly they do not know what information they need to look for.

Something relatively recent in the tool box is being able to meet with faculty to discuss the tools they had available to them at an extension site. One faculty member included in his online course and his short face-to-face interactions with the class encouragement for them to have an appointment with me.

We have the luxury of a writing center to assist students with their writing. We also have an online ticket system combined with Information Technology support to allow us to handle all requests in a unified system.

Our departments merged in January of 2019 to become Library, Information, and Technology Services. This combination of services has resulted in a new kind of synergy in our services. Library personnel are working hard to learn how to answer even more tier one support services.

\section{DREAMING OF THE FUTURE}

One strategy that we have discovered includes integrating LibGuides into our learning management system, Canvas. It can integrate a LibGuide into courses and it allows you to map every course to its own LibGuide if you choose. However, there are too many courses to make it possible to build individual LibGuides for each course. It is more feasible to build them for each discipline, but that still requires more specialized expertise than might be practical. So our strategy 
has become to build a single LibGuide that links to major resources. In the end, at least it embeds resources into Canvas.

Meeting with faculty is, perhaps, the best marketing. A faculty member teaching a course in Tulsa came and met with me, concerned that sufficient resources were available to his students there. We were able to establish that there were indeed enough resources for his students online and that they could set up a meeting with me to coach them through using the resources if they needed it. This proved very useful to some of the students and minorly useful to others. Regardless, this was the best engagement of a single class that I have seen in several years.

Collaborative resources written with the writing center would be very helpful. Our research guide is not bad, but it is really built for a university and was based on that level of material. So, it is perhaps adequate but for graduate work we need to go deeper. This is where working with our writing center would be most helpful. They are uniquely equipped to build resources to help students succeed in their writing.

Perhaps faculty could embed library needs or information literacy needs into their assignments or courses. This strategy starts to influence curriculum and instruction, which can prove difficult or impossible for many libraries. However, the end result would greatly outweigh the effort. We need faculty to encourage and require their students to actually use information in their work and this needs to be information outside of their required texts and lectures. The skills involved in doing so are the kind of general skills that will serve our graduates greatly the rest of their lives!

\section{CURRICULUM ENGAGEMENT}

Until the curriculum is assessed based on student learning in information literacy and research skills the academy is going to fail students in these areas. I am convinced that assessment standards have to be in place to force the issue of information literacy and research throughout the curriculum. There is a common saying that people do what is counted, right? If we have to report or have accountability for something, there is a natural human tendency to work to report positively in those areas. 
This will require influence in curriculum-level decisions that build assessment standards in our institutions. This may prove to be an uphill battle, so to speak, but I think it is worth it. Perhaps this would be a good starting point for an assessment goal or learning outcome: The student will be able to determine an appropriate research method, determine what information is needed for the research question and method being used, access the desired information effectively and efficiently, evaluate the information critically, use the information effectively, and understand the legal and ethical implications in the use of said information.

No, that is not the perfect way to express this, but it is a start. How could this be assessed? Well, there are several possibilities. One would be building a series of assessment rubrics into your learning management system and mapping them to this goal. Another would be developing a juried assessment of a capstone project to determine how well students are integrating these skills into their learning and academic work. There are other ways to do this, but these are a good start.

I encourage all of you to start these conversations, keep pushing for better information literacy and research skill development throughout the curriculum, and never give up hope that change can occur!

\section{ENDNOTES}

1 Asbury Theological Seminary, "Quick Facts: Seminary at a Glance, 2018-2019,” Asbury Seminary website, 2019, https:// asburyseminary.edu/wp-content/uploads/quick-facts.pdf. 